sympathetic towards the part that managers play. ${ }^{11}$ Likewise, after considering the various background characteristics that they could use to prioritise in favour of or against, people are more reluctant to make clearcut decisions-not because they think that because they recognise that the choices are complicated ones.

There is some evidence that surveys, which largely elicit people's initial reactions, and focus groups, which aim to elicit more considered opinions, generate similar results. ${ }^{810}$ The findings reported here suggest otherwise. This leaves a puzzle for future research, but if the within-subject results reported here are found to be generalisable, and if the considered opinions of the general public are required, then doubt is cast on the value of surveys that do not allow respondents the time or opportunity to reflect on their responses.

The study was designed and conducted in collaboration with Professor Mark Baker, Sue Baughan, and Rachel Johns at North Yorkshire Health Authority and Professor Alan Williams at the University of York. We thank them for their input. The authors are indebted to Kerry Atkinson, Vanda King, and Helen Parkinson for painstaking transcription of the group discussions.

Contributors: PD coordinated the project. RC and PD conducted the focus group discussions. BF provided access to choices in health care do not have to be made, but the general practice lists and attended some discussion groups All authors shared equally in the design of the research reported in this paper. PD acts as guarantor. Yorkshire Region Research and Development Office. Competing interests: None declared.

1 NHS Management Executive. Local voices: the views of local people in purchasing for health. London: Department of Health, 1992.

2 Jordan J, Dowswell T, Harrison S, Lilford R, Mort M. Whose priorities? Listening to users and the public. BMJ 1998;316:1668-70.

3 Richardson A, Charny M, Hanmer-Lloyd S. Public opinion and purchasing. $B M J$ 1992;304:680-4.

4 Heginbotham C. Health care priority setting: a survey of doctors, managers and the general public. In: Rationing in action. London: BMJ Publishing, 1993.

5 Fischhoff B. Value elicitation: is there anything in there? Am Psychologist 1991;46:835-47.

6 Lenaghan J, New B, Mitchell E. Setting priorities: is there a role for citizens' juries? BMJ 1996;312:1591-3.

7 Bryan J. Citizens' juries vote to extend nurse roles. $B M J$ 1997;314:773. 1996:319.670-4.

9 Lewis PA, Charny M. Which of two individuals do you treat when only their ages are different and you can't treat both? J Med Ethics 1989;15:2832

10 Bowling A, Jacobson B, Southgate S. Health services priorities: exploration in consultation of the public and health professionals on prioity setting in an inner London health district. Soc Sci Med 1993:37:851-7.

11 Dicker A, Armstrong D. Patient's views of priority setting in health care: an interview survey in one practice. BMJ 1995;311:1137-9.

(Accepted 18 December 1998)
Funding: The project was funded by Northern and

8 Bowling A. Health care rationing: the public's debate. $B M J$

\section{Effect of UK national guidelines on services to treat patients with acute low back pain: follow up questionnaire survey}

\author{
A G Barnett, M R Underwood, M R Vickers
}

In 1994 the UK Clinical Standards Advisory Group recommended eight treatment standards for back pain. ${ }^{1}$ In 1995 availability of these services to general practitioners was generally poor. ${ }^{2}$ We conducted another survey two years later to assess change in availability.

\section{Subjects, methods, and results}

For the 1995 survey we approached a random sample of 342 practices (out of 870) in the Medical Research Council's General Practice Research Framework (a UK-wide network of general practices that participate in research). Of the 307 practices that replied, 290 were still framework members in 1997 and were sent a questionnaire identical with that used in 1995 (study panel). Completing a questionnaire twice can affect responses (panel conditioning). ${ }^{3}$ To assess this effect we randomly selected a second sample from the members of the framework.

Both surveys asked the practices whether eight specified services (see table) had been routinely available to their patients during that financial year (1994-5 and 1996-7) and whether they would refer patients to them if they were available.

Responses obtained in 1997 from practices that had also replied in 1995 were considered equivalent to those approached for the first time in 1997 if the limits of the $95 \%$ confidence interval for the difference in proportion of positive replies were no greater than $10 \%$. For equivalence with $80 \%$ power at the $95 \%$ confidence level, ${ }^{4}$ on the basis of the service "physical therapy before six weeks for patients off work," 211 responses were needed from the second sample. To allow for non-response, we approached 232 practices.

Paired responses from the 1995 and 1997 surveys were compared by using McNemar's test. A logistic regression model including region, list size, and panel membership, as appropriate, was used to assess the effect of fundholding status on the availability of services.

The response rates were $87 \%(251 / 290)$ for the study panel and $85 \%(198 / 232)$ for the second sample. Members of the study panel were representative in terms of region and deprivation score, but larger practices were overrepresented. Response probability was unaffected by region, list size, panel membership, and practice deprivation score. The vast majority of general practices reported that they would use the recommended services if available (ranging from $88 \%$ (urgent referral to a physical therapist) to 99\% (emergency referral for possible cauda equina compression)).

For three services the study panel reported a significantly better service in 1996-7 than in 1994-5 (table). Changes in practices' fundholding status did not explain this. For two of these improved services panel conditioning may have occurred (table). Only for MRC Epidemiology
and Medical Care
Unit, Wolfson
Institute of
Preventive
Medicine,
St Bartholomew's
and the Royal
London School of
Medicine and
Dentistry, Queen 
Availability of recommended back pain services reported by general practices in initial study (1994-5) and in follow up study (1996-7). Values are proportions (percentages) of practices giving valid responses to each question unless stated otherwise

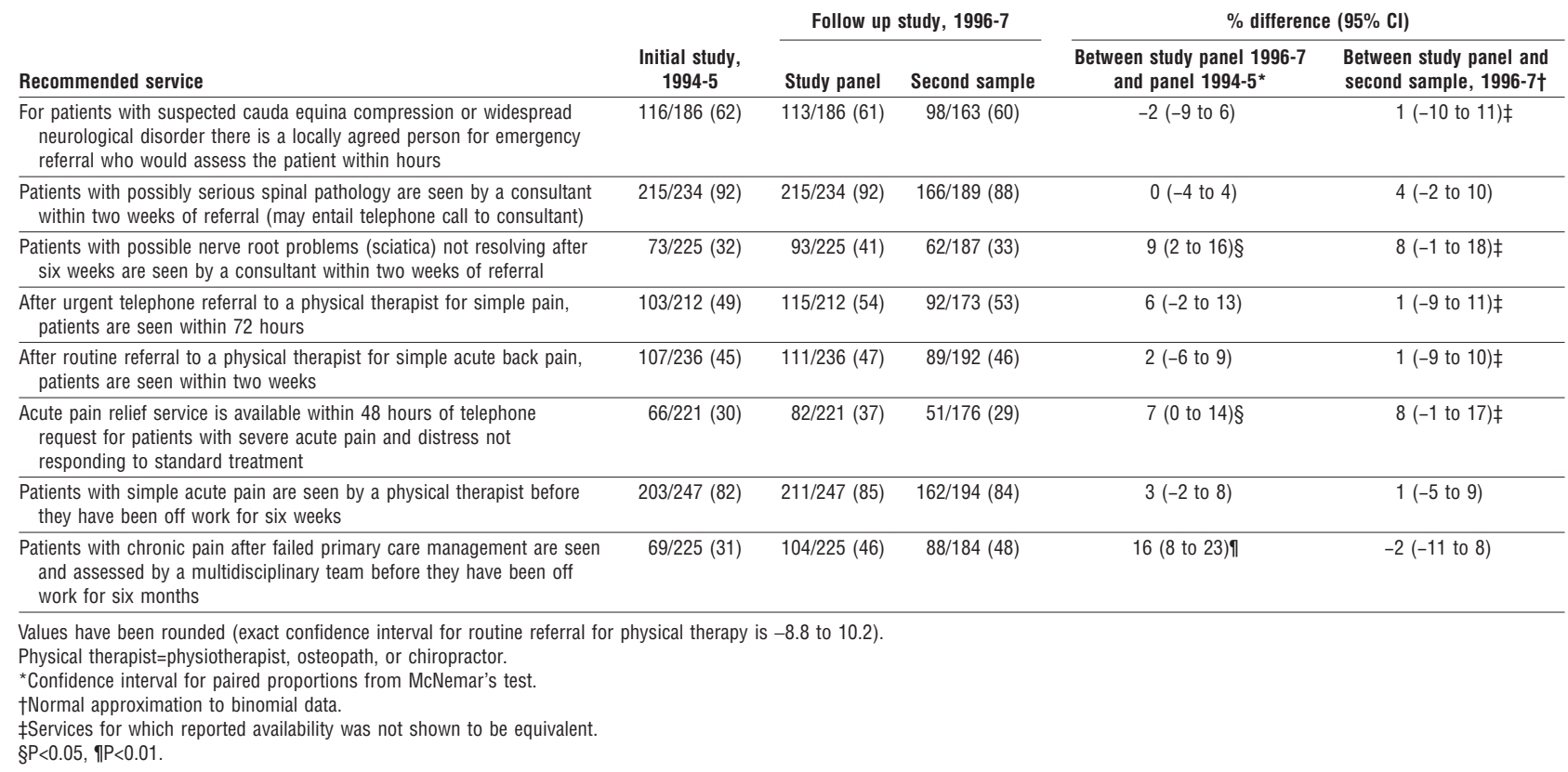

the service "assessment by multidisciplinary team" were responses unaffected by panel conditioning, suggesting a genuinely improved service. Fundholders reported that three services were more available: urgent and routine referrals for physical therapy $(\mathrm{P}=0.01$ and $\mathrm{P}<0.0001$ respectively) and physical therapy before six weeks for patients off work $(\mathrm{P}<0.0001)$.

\section{Comment}

The national guidelines have not had a clear effect on the reported availability of back pain treatments. In contrast, national guidelines on asthma have changed general practitioners' behaviour. ${ }^{5}$ Commercial support for the dissemination and implementation of the asthma guidelines-plus the fact that prescribing recommended drugs is easier than developing services that require additional health authority resourcesmay explain this difference.

Possible explanations for differences between the study panel and the second sample include: $(a)$ the behaviour of practices that complete two questionnaires on the same subject is not typical of all general practices and $(b)$ completing the first questionnaire increased the practices' awareness of the recommendations, leading them to use existing services more efficiently or possibly to influence purchasing decisions.

We did not assess general practitioners' knowledge or application of the advisory group's guidelines. The practices expressed willingness to use the recommended services, and fundholders' ability to provide more physical therapy suggests that efforts to improve access to these services should be focused on the health authorities and primary care groups.

A poster based on this work was presented at a conference held by the World Organisation of National Colleges, Academies and Academic Associations of General Practitioners/Family Physicians in Dublin in June 1998.
We thank Professor T W Meade for advice and support, Mrs Jackie Ross for clerical help, and the many doctors who completed questionnaires.

Contributors: AGB carried out the study and performed the data analysis. MRU had the original idea for the study, developed the questionnaire, and wrote the first draft, subsequently incorporating the ideas of AGB and MRV. MRV supervised all stages of the work. All the authors are guarantors for the study.

Funding: The Medical Research Council and the National Back Pain Association.

Competing interests: None declared.

1 Clinical Standards Advisory Group. Back pain. Report of a CSAG committee on back pain. London: HMSO, 1994.

2 Underwood MR, Vickers MR, Barnett AG. Availability of services to treat patients with acute low back pain. Br J Gen Pract 1997;47:501-2.

3 Moser CA, Kalton G. Further types of sample design. In: Moser CA, Kalton G, eds. Survey methods in social investigation. 2nd ed. Aldershot: Gower, 1971:137-43.

4 Jones B, Jarvis P, Lewis JA, Ebbutt AF. Trials to assess equivalence: the importance of rigorous methods. BMJ 1996;313:36-9.

5 Dennis SM, Vickers MR, Frost CD, Price JF, Barnes PJ. Effect of the asthma management guidelines on recruitment to a RCT of early introduction of inhaled steroids in asthma. Thorax 1997:52(suppl 6):A18.

(Accepted 30 October 1998)

\section{Endpiece \\ Curing a spasm}

This is how you should treat spasms: light a fire on both sides of the bed, administer a potion of mandragora root in a smaller dose than would cause delirium; and put hot poultices on the heels. If fever follows spasm, it stops on the same day or the next or on the next again.

Hippocrates, Places in Man, edited and translated by Elizabeth M Craik, 1998

Submitted by Ann Dally, Wellcome Institute for the History of Medicine 